\title{
An Phased Analysis on the Research of Textile and Costume History in Journal of Silk
}

\author{
Yu Xing ${ }^{1} \&$ Xiaoming Yang ${ }^{1}$ \\ ${ }^{1}$ College of Humanities, Donghua University, Shanghai, China \\ Correspondence: Yu Xing, College of Humanities, Donghua University, Shanghai, China. E-mail: \\ coldie@126.com
}

Received: March 12, 2021

doi:10.5539/ass.v17n4p65

\author{
Accepted: March 19, $2021 \quad$ Online Published: March 31, 2021 \\ URL: https://doi.org/10.5539/ass.v17n4p65
}

\begin{abstract}
The historical theory column "History and Culture" of Journal of Silk is unique in the textile and costume journal industry. Many famous scholars in history and nowadays have written papers on this column. The phased research on the column will help us clarify the academic history and important figures of textile and costume history. Based on the relevant statistics of Journal of Silk, the research concludes that: (1) The name change of historical theory column in Journal of Silk reflects the determination of Journal of Silk whose historical theory column starts from the history of silk and finally extends to the entire history of textile culture and textile technology. (2) The research on clothing history in Journal of Silk can be divided into four periods. 1977-1986 is the budding period, 1987-2003 is the hovering period, 2004-2014 is the stable period, and 2015 is the accelerated development period. (3) The factors of this stage are closely related to the amount of papers published. The changes in the amount of papers published in the previous period are closely related to politics. With the deepening of economic reforms, it is closely related to the reform and development of the textile industry and the development of universities.
\end{abstract}

Keywords: Journal of Silk, Textile and Costume History, Phased Research

Journal of Silk is one of the few professional journals in China that publish papers on the history of textiles and costume, and it is the most important platform for the publication of research results on the history of Chinese textiles and costume (once Journal of Textile Research published papers on the history of textiles and costume, and later no longer published). The quality of the results published in Journal of Silk is of relatively high academic level and academic value across the country, and has cultivated a large number of scholars in the direction of textile and costume history. All major researchers in the field of textile and costume history have been published papers in Journal of Silk. Researching the papers on the history of textiles and costume in Journal of Silk, on the one hand, helps us grasp the development and changes in the history of textiles and costume, research interests, key personnel and major institutions. On the other hand, it is more important to help us accelerate our understanding on the history of textiles and costume itself, based on understanding the academic history of the history of textiles and costume.

\section{Initial History}

\subsection{Relevant Situation of Historical Theory Papers}

Due to the loss of the sample publications of Zhejiang Silk Industry News and Zhejiang Silk related years (1959 1963), the author has no way of knowing whether there was a historical theory column during this period, but he did publish historical theory papers in Zhejiang Silk Industry News. The first issue of Zhejiang Silk Industry News in 1958 published a paper on "Jiangsu's Silk Industry", which was the first historical theory paper in Zhejiang Silk Industry News (Figure 1) (Chen, 1958).

Since then, when Journal of Silk was named in 1964, there was already a "Silk History" column, and 12 papers were published in this year. The first paper "The Strike Struggle between the Existing Stone Tablets on the Site of Hangzhou Jishen Temple and the Silk Weavers of the Qing Dynasty" was published in the first issue (Figure 2)(Zhejiang silk historical materials compilation room, 1964), this is the first historical theory paper in the history of Journal of Silk (after it determined the name).The author cut down the relevant papers on the column of "Silk History" in the catalog page of Journal of Silk in 1964 (Figure 3). From Figure 3, we can find that the "Silk History" column has two characteristics: 


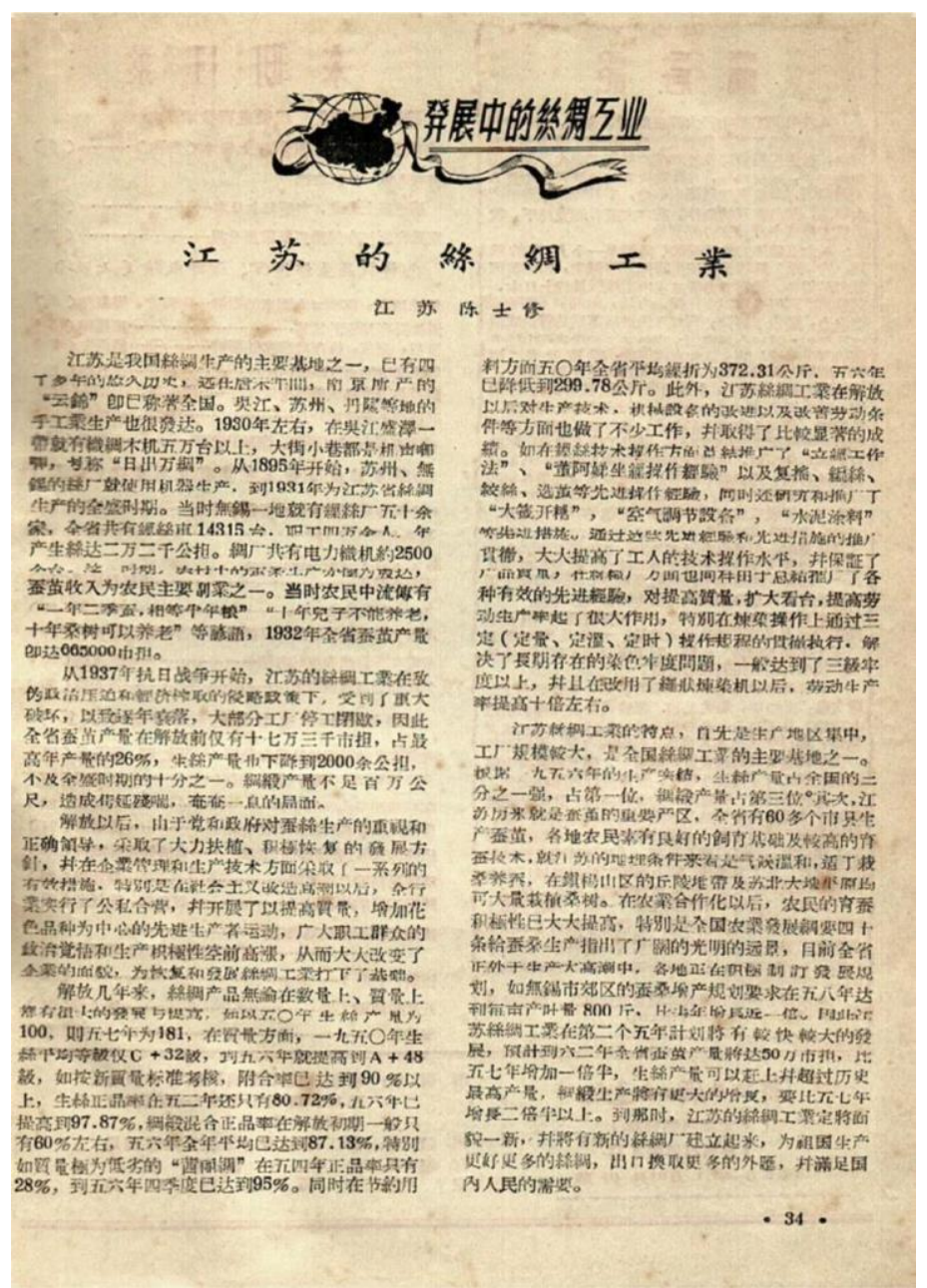

Figure 1. The first historical theory paper in Zhejiang Silk Industry News

(1) From the 1th Journal of Silk in 1964 to 11th, the column of "Silk History" moved from the inner page to the second and third front cover, which shows that the editorial department is paying more and more attention to the construction of this columns and intends to build it to be the magazine's brand. We can also get a glimpse of the artistry of the logo patterns in the column (Figure 4). Because the printing technology at that time was still movable type printing, drawing pictures was quite troublesome, but the Journal did not hesitate to spend time and labor to make these logo patterns at that time, which shows that the column of "Silk History" was valued.

(2) In Journal of Silk, the authors of historical theory are mainly Zhejiang Silk Historical Materials Compilation Room and Gu Fangsong. The Zhejiang Silk Historical Data Collection Office was established by Zhu Xinyu in the early 1960s when Zhu Xinyu was the deputy director of the Zhejiang Provincial Department of Light Industry and the director of the Silk Bureau. It specializes in the collection and sorting of Zhejiang silk historical materials. It was forced to stop working during the "Cultural Revolution". Gu Fangsong (1932 ), whose pen name is Gu Song, was from Dongyang, Zhejiang. He is good at the history of arts and crafts. In 1955, he graduated from the Design Department of Lu Xun College of Literature and Art. In 1956, he worked in the theoretical research room of the Central Academy of Arts and Crafts. In 1961, he was transferred to the Department of Arts and Crafts of Zhejiang Academy of Fine Arts as a teacher of Chinese Arts and Crafts History. He is a professor at the China Academy of Art and the chairman of the Zhejiang Folk Artists Association. He successively participated in the compilation of "Cihai" art volume, "Encyclopedia" art volume, "Chinese History Encyclopedia Chinese Art" and so on. His monographs include "Research on Phoenix and Bird Patterns" and "Dunhuang Patterns". His papers include "Overview of Auspicious Patterns" and so on. In 1994, he completed the creation of "Longevity Picture". Gu Fangsong successively published ancient silk patterns in Journal of Silk in 1964. 
From the 12th issue of 1964 to the 8th issue of 1966, the publication of the "Silk History" column in Journal of Silk was canceled (The office of Journal of Silk, 1964-1966). There are no more historical theory papers published here.

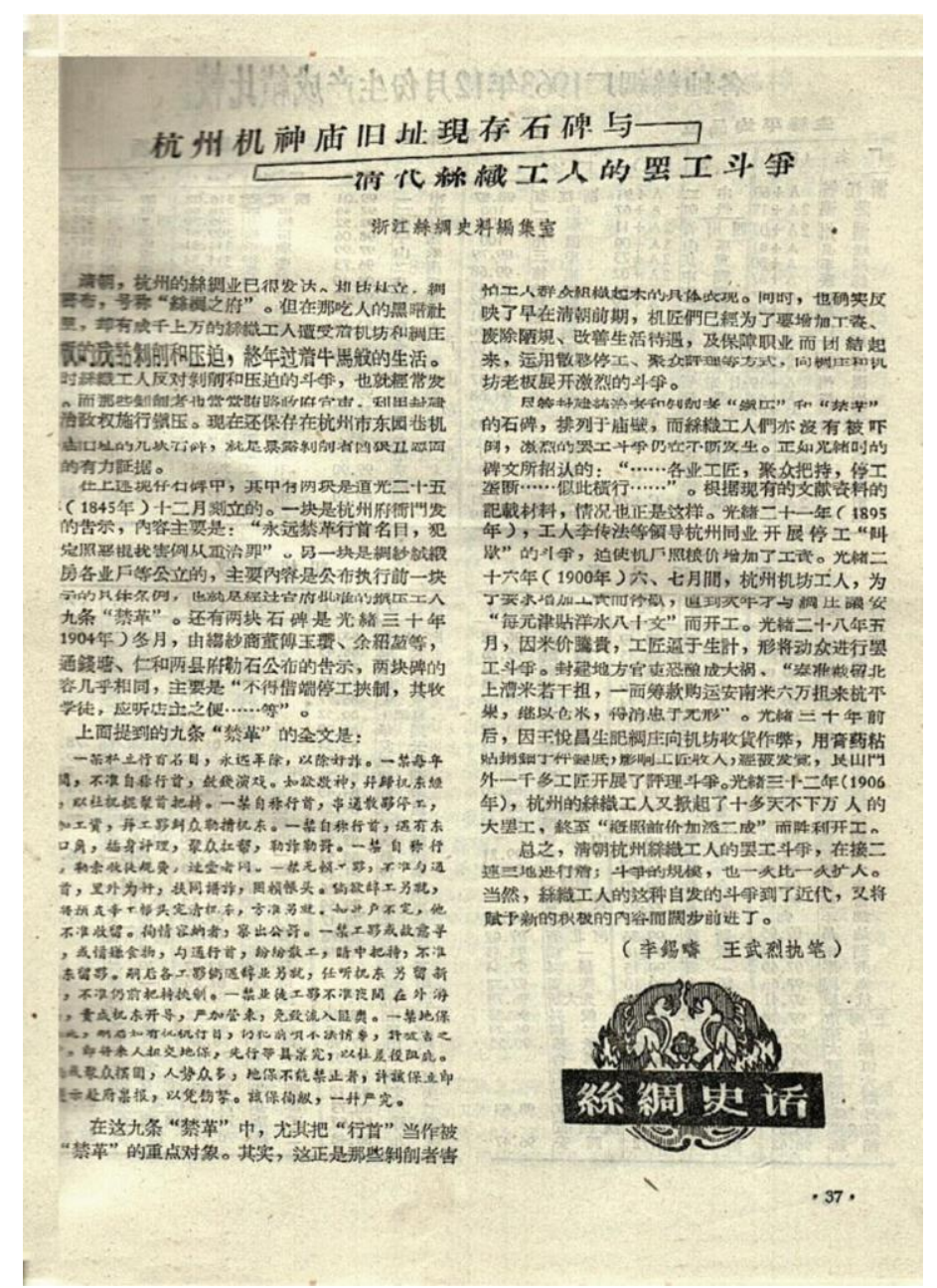

Figure 2. The first historical theory paper published in the history of Journal of Silk (No. 1, 1964)

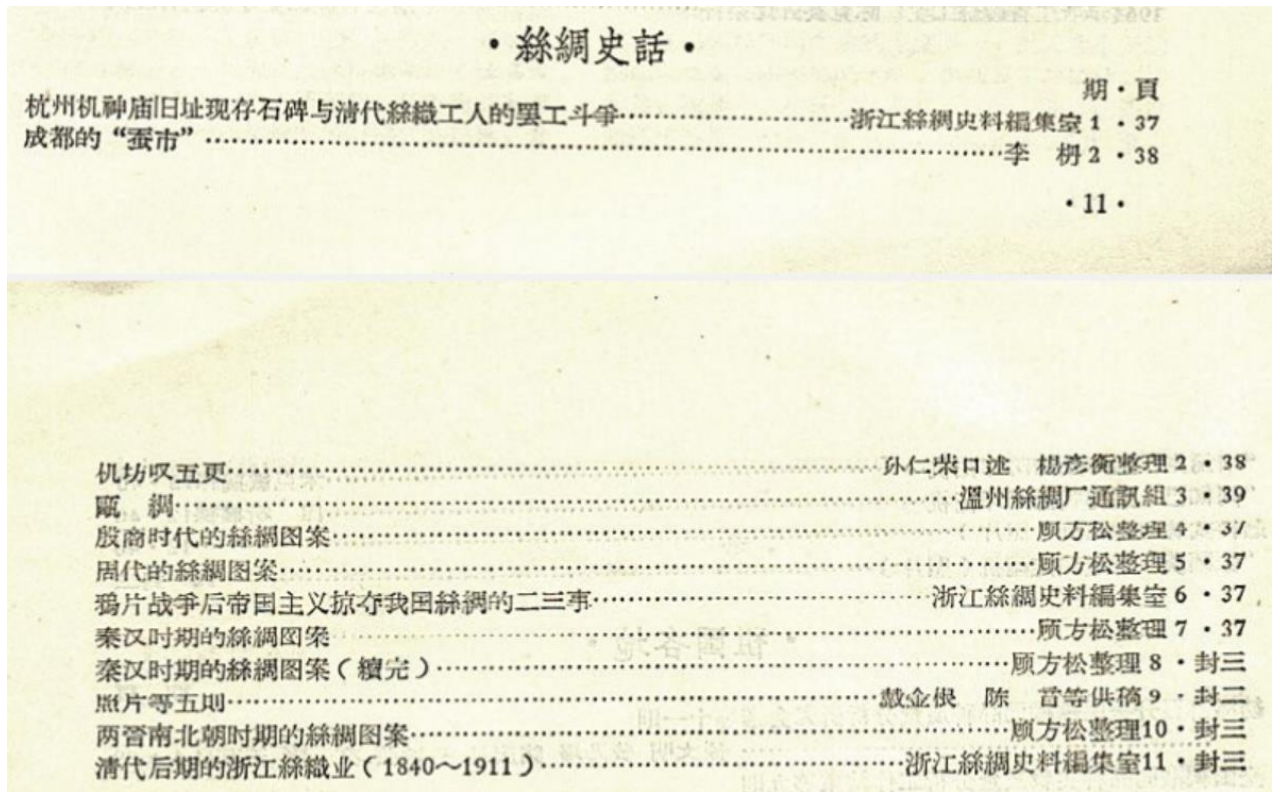

Figure 3. Papers published in "Silk History" in Journal of Silk in 1964 

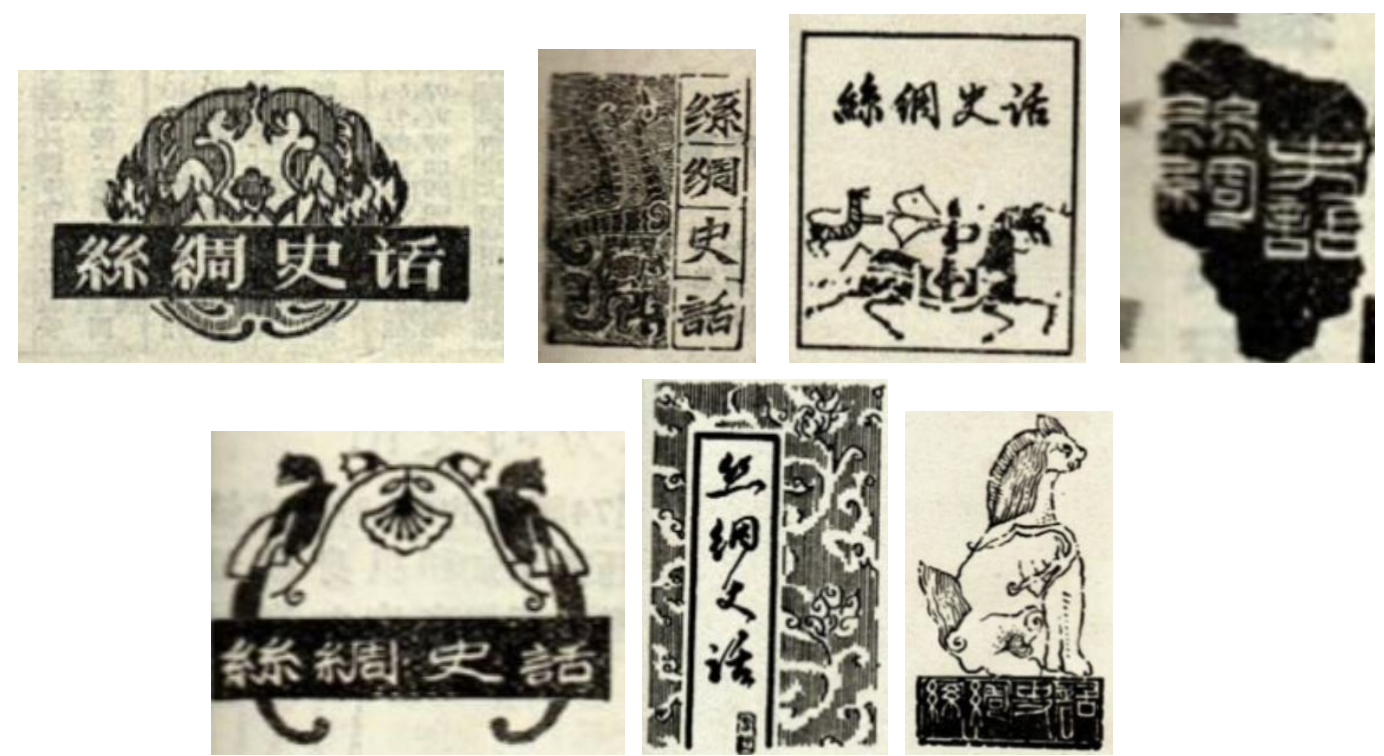

Figure 4. The "Silk History" column logo of Journal of Silk in 1964

\subsection{Analysis of the Reasons for Discontinued Historical Theory Columns}

The reason why Journal of Silk briefly appeared in the direction of history is that when the first issue of 1964 was finalized, the column "History of Silk" was deliberately held, but it was stopped since the 11th issue (November). The author believes that this is related to the political environment at that time. Because in January 1964, the Central Committee of the Communist Party of China held a symposium on literature and art work to criticize ghost dramas such as "Li Hui Niang" and "Xie Yaohuan". Subsequently, various literary and artistic associations and literary and artistic department under the Ministry of Culture carried out rectification. At the same time, a large-scale political criticism towards a number of literary works has been carried out in major newspapers and periodicals across the country. This critical movement undermined the Communist party's "double-hundred" policy, and the cultural prosperity that appeared in the period of national economic adjustment was aborted. This incident has an impact on Journal of Silk. The editorial department is worried that the political criticism movement will expand, resulting in "Silk History" papers being criticized as literary works, causing unnecessary trouble to the editorial department and the publication. Of course, this approach is quite correct, as the historian Wu Han's history monograph was involved in political struggle in 1965 fully proved this point. It was not until 1977 that the "Gang of Four" was overthrown in 1976 that the historical theory papers were re-included in 1977, which shows that the absence of historical theory papers in the previous 10 years was indeed determined by the political situation.

\section{The Related Development Situation of the Historical Theory Column after the Suspension of Publication of Journal of Silk}

\subsection{Changes in the Historical Theory Columns}

After Journal of Silk resumed its suspension in 1971, its first column of historical theory commentaries did not follow the original column name "Silk History" of the original Journal of Silk (Journal of Silk in 1966 and before). The paper titled "Ancient Silk from the Tomb of Zhou Yu in the Southern Song Dynasty" included in the 2th issue of 1977 was titled "Ancient Silk"(Wu, 1977). The column of historical theory commentaries in the 5th issue of 1979 was called "Historical Draft"(Zhang, 1979). In 1980, there was no historical theory column, but there was an paper on historical theory "History of Sericulture and Silk"(Han, 1980). In 1981, the column of historical theory was called "Historical Data Textual Research", and there was only one paper on "Verification of Silk Fabrics Unearthed by Qian Shanyang"(Xu, Qu, Li, \& Zhang, 1981). In 1982, the historical theory column was restored to the original "Silk History" column(The office of Journal of Silk, 1982). From 1983 to 1986, the historical theory column was renamed "Silk History Research"(The office of Journal of Silk, 1983-1986). From 1987 to 1990, the historical theory column was renamed "historical archaeology"(The office of Journal of Silk, 1987-1990). From 1991 to the present, the column of historical theory has been "History and Culture"(The office of Journal of Silk, 1991).

The name change in the historical theory column of Journal of Silk shows that it starts from the history of silk 
and finally extends to the entire history of textile culture and textile technology.

\subsection{Related Statistical Data}

In 1971, Journal of Silk resumed its publication. It was originally named Silk Intelligence and was renamed Silk News in 1973. However, none of the historical theory papers were published. This is related to the purpose of the publication, because these two periodicals mainly provide industry consulting, technical training and other aspects.

After 1971, all the papers of Journal of Silk (after the suspension of publication) can be retrieved on CNKI. The author can get the total number of papers per year through annual search. However, the last issue of Journal of Silk from 1971 to 1973 , 1976 to 1977 , and 1995 to 2004 did not have a full-year catalog. The author made statistics on historical theory papers based on the relevant historical theory column in the original text. From 1978 to 1994, and the last issue of each year after 2005, there is a catalogue. The author makes statistics on historical theory papers based on the relevant historical theory column in the catalogue, and obtains Table 1. Although a small part of the papers in other columns can also be used for the direction of historical theory, the author will not make statistics here, because they are mostly applied to modern design with ancient cultural relic patterns or techniques.

Table 1. The number of papers on textile history and the total number of papers in the past years after the official resumption of the suspension of Journal of Silk

\begin{tabular}{|c|c|c|c|c|c|c|c|c|c|}
\hline Time & $\begin{array}{c}\text { Number of Papers on } \\
\text { Textile History/ } \\
\text { Total Number of Papers }\end{array}$ & Time & $\begin{array}{c}\text { Number of Papers on } \\
\text { Textile History/ } \\
\text { Total Number of Papers }\end{array}$ & Time & $\begin{array}{c}\text { Number of Papers on } \\
\text { Textile History/ } \\
\text { Total Number of Papers }\end{array}$ & Time & $\begin{array}{c}\text { Number of Papers on } \\
\text { Textile History/ } \\
\text { Total Number of Papers }\end{array}$ & Time & $\begin{array}{l}\text { Number of Papers on } \\
\text { Textile History/ } \\
\text { Total Number of Papers }\end{array}$ \\
\hline 1971 & $0 / 22$ & 1982 & $4 / 358$ & 1993 & $12 / 411$ & 2004 & $24 / 296$ & 2015 & $30 / 169$ \\
\hline 1972 & $0 / 53$ & 1983 & $4 / 385$ & 1994 & $17 / 375$ & 2005 & $23 / 285$ & 2016 & $35 / 169$ \\
\hline 1973 & $0 / 131$ & 1984 & $3 / 421$ & 1995 & $16 / 355$ & 2006 & $22 / 292$ & 2017 & $32 / 172$ \\
\hline 1975 & $0 / 213$ & 1986 & $4 / 364$ & 1997 & $14 / 318$ & 2008 & $22 / 288$ & 2019 & $54 / 263$ \\
\hline 1976 & $0 / 187$ & 1987 & $14 / 351$ & 1998 & $20 / 320$ & 2009 & $24 / 248$ & 2020 & $75 / 312$ \\
\hline 1977 & $1 / 218$ & 1988 & $9 / 351$ & 1999 & $7 / 346$ & 2010 & $28 / 295$ & & \\
\hline 1978 & $0 / 289$ & 1989 & $13 / 348$ & 2000 & $5 / 351$ & 2011 & $34 / 283$ & & \\
\hline 1979 & $1 / 261$ & 1990 & $13 / 427$ & 2001 & $11 / 337$ & 2012 & $32 / 250$ & & \\
\hline 1981 & $1 / 315$ & 1992 & $13 / 396$ & 2003 & $0 / 288$ & 2014 & $22 / 177$ & & \\
\hline
\end{tabular}

From Table 1, we can see five characteristics:

(1) The historical direction of Journal of Silk was formally reverted in 1977.

(2) The period from 1977 to 1986 is a period of infancy, and the number of papers per year is less than 10.

(3) The period from 1987 to 2003 was a wandering period. Some years contained less papers and some years contained more papers. Not all columns existed for the period.

(4) The period from 2004 to 2014 is a stable period, with columns set up in each issue, basically about 2 papers per issue.

(5) 2015 has been in a period of accelerated development, and the proportion of its papers is getting higher and higher.

The reason for this staging situation is closely related to social changes.

(1) These years from 1977 to 1986 were the embryonic period. After the "Cultural Revolution", the political environment was more relaxed than before. Historical theories sometimes involve some ancient political statements, and some authors are afraid to write. Journal of Silk may receive limited manuscripts. This was the author's reason, and there is also the concern of Journal of Silk in it, so the number of publications is limited.

(2) The reason why these years from 1987 to 2003 were a lingering period is that the comprehensive economic reform in 1985 has been implemented for two years, and the basic policies have been basically stable, which gave Journal of Silk some reassurance. In the meantime, the strategy of rejuvenating the country through science 
and education was proposed in 1995, and the subsequent expansion of college enrollment triggered the establishment of a series of independent colleges and universities, including those with textile and clothing majors, which led to the expansion of graduate education by colleges and universities with the right to enroll masters and doctors. The expansion of postgraduate enrollment meet market needs, to a certain extent, which promotes the establishment of historical theory in the direction of postgraduate training in textile and costume colleges, which does not avoid the need for publication of papers. This is the reason why the publication of historical theory papers in Journal of Silk increased during this period. At the same time, the reform of state-owned enterprises implemented in 1998 had a significant impact on the textile industry. The textile industry was generally not very good from the end of the 1990s to the beginning of the 21st century, which triggered Journal of Silk to make some adjustments according to the external environment. As an engineering journal, Journal of Silk always has the idea of strengthening its main business. In addition, with the expansion of the influence of Peking University's core catalogue, as a journal that has always been in its catalogue, Journal of Silk has always insisted on improving the quality of the publication and the continuous increase in the citation rate of papers. After all, historical theory is a niche discipline, the citation rate is much lower than that of engineering disciplines, which is the reason why Journal of Silk has reduced its number of papers. In short, during this period, Journal of Silk was also in the midst of wandering.

(3) From 2004 to 2015, Journal of Silk confirmed the existence of the historical theory column "historical culture" and provided certain support. It was a period of stability. There were two main reasons: (1) The reform of state-owned enterprises has basically ended, the textile industry has been reorganized and upgraded, and the entire industry has recovered and prospered, giving strong advertising funding support to Journal of Silk, which relies on industrial development. (2) As a characteristic column that has existed for decades, the historical theory column of Journal of Silk was the most characteristic column in the textile journals at that time, and it was also the only one. It was irreplaceable and had its own charm. It is difficult for the publisher to give up.

(4) In 2015, as China paid more and more attention to the construction of national culture, textile intangible cultural heritage research began to rise, and major research teams such as Donghua University, Jiangnan University, Suzhou University, Wuhan Textile University, and Xi'an Polytechnic University emerged. The number of manuscripts received by Journal of Silk has soared, and the quality has been continuously improved, which has exacerbated the imbalance between supply and demand. Therefore, under this situation, Journal of Silk expanded the amount of papers in the historical theory column to adapt to the development of the new situation, so it was accelerated development period.

\section{Conclusion}

The phased study of the textile and costume history research in Journal of Silk cannot be based on the change of the supervisor, because the supervisor has little influence on the journal. Only the organizer has a great influence on the journal. The influence of the organizer on the journal mainly reflects the name of the column and the amount of papers. Based on the change statistics of the column names and historical statistics of the number of papers, the research concludes that: (1) The name change of historical theory column in Journal of Silk reflects the determination of Journal of Silk whose historical theory column starts from the history of silk and finally extends to the entire history of textile culture and textile technology. (2) The costume history research in Journal of Silk can be divided into four periods. 1977-1986 is the budding period, 1987-2003 is the hovering period, 2004-2014 is the stable period, and 2015 is the accelerated development period. (3) The factors of this stage are closely related to the amount of papers published. The changes in the amount of papers published in the previous period are closely related to politics. With the deepening of economic reforms, it is closely related to the reform and development of the textile industry and the development of universities.

\section{References}

Chen, S. X. (1958). Jiangsu's Silk Industry. Zhejiang Silk Industry News, (1), 34.

Zhejiang silk historical materials compilation room. (1964). The Strike Struggle between the Existing Stone Tablets on the Site of Hangzhou Jishen Temple and the Silk Weavers of the Qing Dynasty. Journal of Silk, (1), 37 .

The office of Journal of Silk. (1964). 1964 General Catalog. Journal of Silk, (12), General Catalog.

The office of Journal of Silk. (1965). 1965 General Catalog. Journal of Silk, (12), General Catalog.

The office of Journal of Silk. (1966). Catalog. Journal of Silk, (1), Catalog.

The office of Journal of Silk. (1966). Catalog. Journal of Silk, (2), Catalog. 
The office of Journal of Silk. (1966). Catalog. Journal of Silk, (3), Catalog.

The office of Journal of Silk. (1966). Catalog. Journal of Silk, (4), Catalog.

The office of Journal of Silk. (1966). Catalog. Journal of Silk, (5), Catalog.

The office of Journal of Silk. (1966). Catalog. Journal of Silk, (6), Catalog.

The office of Journal of Silk. (1966). Catalog. Journal of Silk, (7), Catalog.

The office of Journal of Silk. (1966). Catalog. Journal of Silk, (8), Catalog.

Wu, W. H. (1977). Looking at ancient silk fabrics from the tomb of Zhou Yu in the Southern Song Dynasty. Journal of Silk, (2), 13-19.

Zhang, B. F. (1979). The quality, specification and inspection of ancient silk fabrics in my country. Journal of Silk, (5), 53.

Han, L. (1980). History of Sericulture and Silk. Journal of Silk, (8), 49-51.

Xu, H., Qu, Q. M., Li, M. S., \& Zhang, H. Z. (1981) .Verification of silk fabrics unearthed in Qian Shanyang. Journal of Silk, (2), 43-45.

The office of Journal of Silk. (1982). The General Catalogue of Journal of Silk in 1982. Journal of Silk, (12), 61.

The office of Journal of Silk. (1983). The General Catalogue of Journal of Silk in 1983. Journal of Silk, (12), 68.

The office of Journal of Silk. (1984). The General Catalogue of Journal of Silk in 1984. Journal of Silk, (12), 68.

The office of Journal of Silk. (1985). The General Catalogue of Journal of Silk in 1985. Journal of Silk, (12), 60.

The office of Journal of Silk. (1986). The General Catalogue of Journal of Silk in 1986. Journal of Silk, (12), 60.

The office of Journal of Silk. (1987). The General Catalogue of Journal of Silk in 1987. Journal of Silk, (12), 60.

The office of Journal of Silk. (1988). The General Catalogue of Journal of Silk in 1988. Journal of Silk, (12), 60.

The office of Journal of Silk. (1989). The General Catalogue of Journal of Silk in 1989. Journal of Silk, (12), 60.

The office of Journal of Silk. (1990). The General Catalogue of Journal of Silk in 1990. Journal of Silk, (12), 69.

The office of Journal of Silk. (1991). The General Catalogue of Journal of Silk in 1991. Journal of Silk, (12), 69.

\section{Copyrights}

Copyright for this article is retained by the author(s), with first publication rights granted to the journal.

This is an open-access article distributed under the terms and conditions of the Creative Commons Attribution license (http://creativecommons.org/licenses/by/4.0/). 